\title{
The structure of working hours in Swiss companies
}

\author{
Norbert Thom and Adrian Blum
}

\section{Preface}

The change in our society's set of values and the requirements of dynamic markets (shorter product life-cycles, increasing speed of innovation, greater customerorientation, internationalization, etc.) present companies with an increasing number of new challenges. These challenges are not only found in the development of new products, production technologies, etc. but are also found in connection with time and flexibility, in particular. Both theory and practice require new solutions in respect of working hours and their flexibilization. Which flexible models of working hours are being used in Swiss companies today, which factors have influenced their introduction and which aspects of working-hour structures should receive more attention in future in the opinion of those involved - these questions are the basis of this contribution.

\section{INITIAL SITUATION AND RESEARCH STATUS}

The increasing number of books and magazines published on this topic are indications that the structure of working hours has gained strongly in importance in recent years. This is particularly true since the flexibilization of working hours is frequently assumed to be an attempt to solve and curb the social and economic consequences of the increasing frequency of restructuring operations, mergers, takeovers, etc. Targets such as the creation of new jobs, an improved integration of family, leisuretime and profession or a more comprehensive consideration for the new structures of employees' requirements in the direction of more holistic lifetime careers generally receive prominence in the broad-based discussions on the flexibiliza- 
tion of working hours. The multiple layers inherent in these objectives make recognition of the basic trends difficult in economic research into working hours.

It is remarkable that, so far, no research work has been done to demonstrate a comprehensive view of human resource and organizational aspects of working-hour flexibilization. Hardly any attention has been paid to the important effects caused by the introduction of new working-hour models on the human resource management (e.g. leadership) and organizational (e.g. organization of work) sectors of a company which affect all hierarchical levels and functional areas and are extremely varied (e.g. influence on the individual performance of employees). The aim of this contribution is to give the initial conceptual and empirical basic data from the authors' research project which aims to integrate the problem area of working-hour flexibilization into a comprehensive staffing and organizational concept. In order to obtain basic data, the authors conducted a widespread empirical survey (mail survey) which was based on the following enquiries: ${ }^{1}$

- Which instruments, methods and approaches are used in practice to determine working hours in Switzerland?

- Which factors are favourable or unfavourable for the introduction of flexible working-hour models? (The focus of this contribution is primarily on the first two aspects.)

- Which aspects of working-hour structures should be given more attention in the future?

A total of 905 randomly selected companies in Switzerland participated in the study (random samples from different business branches). $79 \%$ of the companies included are in the Germanspeaking part of Switzerland and $21 \%$ are in the French-speaking part. These mainly consisted of small and medium-sized companies (up to 500 employees) in the manufacturing (55\%) and service sectors $(38 \%)$. The large companies (5\%) interviewed in the survey are mainly active in the service sector. Public administrations and social insurances were the most frequent types $(9.3 \%)$, followed by the food, beverage and luxury goods industry (7.3\%), construction 
industry $(7.1 \%)$, power and water supply together with mining $(5.2 \%)$ as well as metalworking and metal-processing $(5.1 \%)$. Although, from a statistical point of view, the results of the evaluation cannot permit any representative statements to be made, they provide a very informative description of the current structures of working hours in Swiss companies.

\section{WORKING HOURS: MODELS AND FEATURES}

A difference is frequently made in theory and practice between traditional and flexible working-hour models. But where can the line be drawn between these two categories? The features of each category are given below:

Traditional working hours are mainly strictly regulated, which means minimum freedom for both the company and the individual. With this model of working hours, a difference can be made between classic full-time work and conventional part-time work. Conventional part-time work refers to a working relationship that is shorter than the (company's) usual working hours. Normally, working hours take place according to a fixed schedule, i.e. the work is regulated to several hours every day or concentrated on several days in the week dependent on the period of reference. This study differentiates between (fixed) part-time work with an employment level of up to 50 percent and (fixed) part-time work with an employment level of 50 to 90 percent.

Flexible working hours permit a clear deviation from the traditional, rigid normal working hours and are considered to be flexible in this study when they are chronometric (variation in the length of working hours) and/or chronological (variation in the positioning of working hours) mixed types. This subdivision is based on a subjective decision by the authors and leads to both a transparent and fairly broad view of flexible working hour models. As a result, 
capacity-oriented variable working hours can be categorized as flexible for example, although, primarily, they mainly provide the employer with flexibility. Fig. 1 shows the most important characteristics of the flexible working-hour models investigated. ${ }^{2}$ The types of working hours used in practice can have other features than the models listed below, since the models are frequently designed to suit the demands of specific companies. The aim of this investigation was not to determine precise lines of demarcation between the working-hour models used. The focus here is on the recognition of trend types, which permit the formulation of typical and exemplary statements on the structure of Swiss working hours. 


\begin{tabular}{|c|c|}
\hline $\begin{array}{l}\text { Working-hour } \\
\text { model }\end{array}$ & Features \\
\hline $\begin{array}{l}\text { Capacity-oriented, } \\
\text { variable working hours } \\
\text { (on-call work) }\end{array}$ & $\begin{array}{l}\text { - Total nominal manhours (e.g. one month). } \\
\text { - The employees are mostly called in at short notice and only receive a wage when actually } \\
\text { working (in normal cases). } \\
\text { - Employer has greater power to decide. }\end{array}$ \\
\hline Bandwidth model & $\begin{array}{l}\text { Variability of work volume within certain limits (with effects on the amount of income and/or } \\
\text { the number of days off). } \\
\text { - The upper and lower limits of the working hours stipulated in a week determine the bandwidth } \\
\text { of possible alternatives. }\end{array}$ \\
\hline Flexitime & $\begin{array}{l}\text { Division of daily work into core times (when attendance is required) and flexible times (own } \\
\text { individual requirements). } \\
\text { - A specified nominal period of time is to be met within a scheduled period of time } \\
\text { - Limited or unlimited time credits can generally be carried forward into the next accounting } \\
\text { period. }\end{array}$ \\
\hline Variable working hours & $\begin{array}{l}\text { - A further development of flexitime, i.e. no differentiation is made between flexible times and } \\
\text { core times. } \\
\text { - Working hours can be chosen freely within a predetermined timeframe. }\end{array}$ \\
\hline Shift work times & - Individual workplaces are occupied by several employees during different working periods. \\
\hline Job-sharing & $\begin{array}{l}\text { - Sharing one job between two or more employees in respect of the location and duration of } \\
\text { working hours as well as content aspects. } \\
\text { Those concerned bear joint responsibility; there is also the duty of representation and simulta- } \\
\text { neous right to give notice. However, these outline conditions are frequently only used in prac- } \\
\text { tice in a highly weakened form. }\end{array}$ \\
\hline Annualised hours & $\begin{array}{l}\text { - Agreement of an annual individual nominal working time. The arrangement of working time is, } \\
\text { however, determined during the year dependent on the amount of work. } \\
\text { - Even though the hours worked vary widely dependent on period, the employer pays the annual } \\
\text { income in equal monthly part-payments. }\end{array}$ \\
\hline Sabbaticals & $\begin{array}{l}\text { Long-term vacations (from approx. } 3 \text { months) while still maintaining a working relationship } \\
\text { (excluding absences due to military activities). } \\
\text { - Sabbaticals can be saved up using time credits or granted by other regulations with full, partial } \\
\text { or no wage compensation. } \\
\text { - Purpose: e.g. compensation for fluctuating order levels, language course, further training, } \\
\text { recuperation. }\end{array}$ \\
\hline $\begin{array}{l}\text { Flexible/gradual retire- } \\
\text { ment schemes }\end{array}$ & $\begin{array}{l}\text { - Flexible pension schemes: The employees can freely choose when they wish to retire. } \\
\text { - Gradual pension schemes: No fixed point in time for retirement, no leaving the company } \\
\text { abruptly. The emphasis is on a successive transition to retirement over a longer period of time. }\end{array}$ \\
\hline $\begin{array}{l}\text { Extension of working } \\
\text { life }\end{array}$ & - Even after reaching retirement age, employment is made possible in the company. \\
\hline $\begin{array}{l}\text { Teleworking/working at } \\
\text { home }\end{array}$ & $\begin{array}{l}\text { - Teleworking/working at home can be classified in various types of working: teleworking at } \\
\text { home, alternating teleworking (alternating between two workplaces: e.g. between the work- } \\
\text { place in the company and the workplace at home), collective teleworking (working in neigh- } \\
\text { bourhood or satellite offices) and mobile teleworking (working independent of location: e.g. in } \\
\text { fieldwork). } \\
\text { - These working forms cannot be directly assigned to the working-hour models, since they pri- } \\
\text { marily represent a possibility of decentralized working. Flexibilization of the workplace, how- } \\
\text { ever, is particularly well-suited to variation in positioning and duration of working hours. }\end{array}$ \\
\hline $\begin{array}{l}\text { Time-autonomous } \\
\text { working groups }\end{array}$ & $\begin{array}{l}\text { - Individual working groups decide freely and on their own authority on the distribution of their } \\
\text { working times. } \\
\text { - The time schedule determined by those responsible is autonomously divided up and adminis- } \\
\text { tered by the individual group members. } \\
\text { - The group (as a unit) generally has to keep to certain attendance times or to minimum working } \\
\text { hours in order to ensure that the department continues to function. }\end{array}$ \\
\hline
\end{tabular}

Fig. 1: $\quad$ Flexible working hours: models and features 


\section{THE STRUCTURE OF WORKING HOURS IN SWISS COMPANIES: EMPIRICAL RESULTS}

\subsection{Working-hour models and their spread}

Around $70 \%$ (647) of the 905 companies in the survey already use flexible working-hour models. In a further 5\% (44) of cases, the introduction of models of this type is at least planned for the near future. Only approximately one quarter (214) of the companies do not have or are not planning on having flexible working-hour models.

The noticeably high proportion of companies which have already introduced or are planning on introducing flexible working-hour models, however, should not conceal the fact that, in these companies, flexitime only rarely applies to all employees. In most cases, only particular functional areas or groups of employees are affected by it. In fact, all employees only benefited from flexible working hours in $13.5 \%$ of the companies investigated and, in more than half of the companies, only a maximum of $25 \%$ of the staff were able to take advantage of such working hours.

When analyzed from the aspect of company size, it was evident that the greater the number of employees, the more frequently were flexible working-hour models used. The proportion of companies with flexible working-hour models was $93.8 \%$ in the category "large companies", $82.9 \%$ in "medium-sized companies" and $65.2 \%$ in "small companies". A breakdown into sectors or business branches and linguistic regions reveals no differences worth mentioning.

Flexitime $(73.4 \%)^{3}$ and traditional models of working hours as well as fixed part-time jobs (66.1\% and $56.2 \%)$ together with rigid $100 \%$ jobs $(62.4 \%)$ were the most frequent working time arrangements (cf. Fig. 2, p. 7). Other "classic" models such as capacity-oriented variable working hours (45.7\%) and shiftwork models (44.7\%) are also frequently used. 


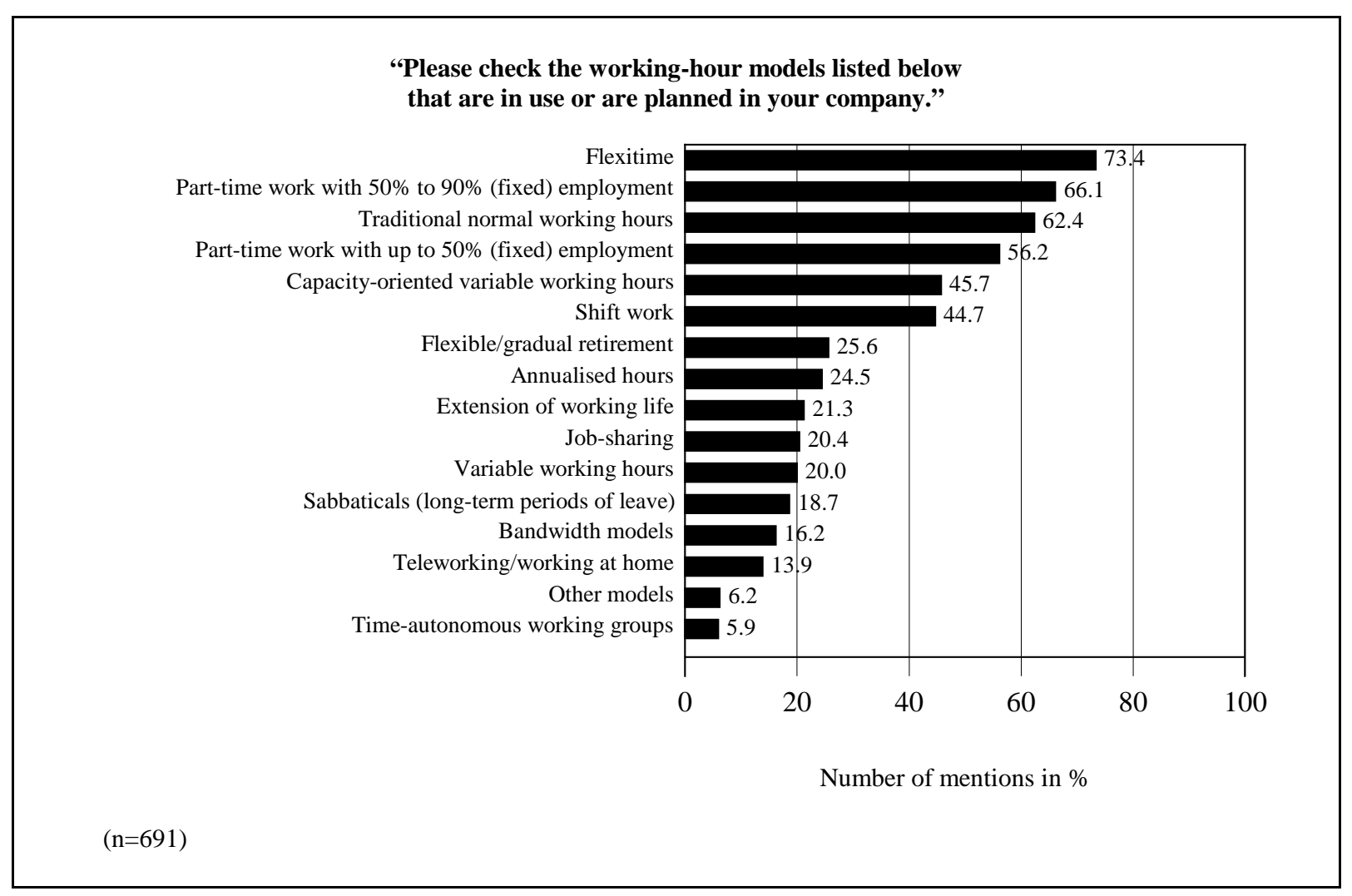

Fig. 2:

Overall frequency of working-hour models in Swiss companies (multiple mentions, all business branches, all functional areas)

It is noticeable that a major proportion of the companies in the survey that use flexible working hours only apply working-hour models with a low degree of flexibility or ones that had proved themselves over a long period:

- With one exception (flexitime), the most widely used working-hour models display very limited free-time opportunities for employees. Both capacity-oriented variable working hours as well as shiftwork are primarily designed to meet employers' requirements. Employees gain no additional control over their time worth mentioning with these models.

- The most frequently used working-hour models can be viewed as "classic" flexible models. Where flexitime is concerned, this is a working-hour model that has proved itself in practice for around thirty years and has not changed substantially in most cases. 
Approximately $20 \%$ to $25 \%$ of the companies use working-hour models with a long period of reference. This includes forms of flexible and gradual retirement, annualised working-hour models as well as possibilities for continuing to employ staff after they reach retirement age. Benefits such as compensation for fluctuating order levels, avoiding dismissals as well as retaining experience and know-how are all contributory factors to their use. Working-hour models with a fairly high degree of flexibility (in particular, high level of time autonomy for those affected), i.e. teleworking (13.9\%) and time-autonomous working groups (5.9\%) are only used in individual cases.

\subsection{Working-hour structures: influential factors}

Different human resource and organizational factors (e.g. employees' requirements) affect the structure of working hours within a company. Factors of this nature can either favour or hinder the introduction of flexible working-hour models. For this reason, the heads of human resources selected were asked about possible influential factors which they could evaluate using a six-point ranking scale (absolutely unimportant (1), unimportant (2), rather unimportant (3), rather important (4), important (5) and highly important (6)). To enable comparisons to be made between the individual factors, the arithmetic average achieved in the assessment is given in brackets.

\section{a) Positive influential factors}

Person-oriented factors such as "creation of more attractive working conditions" (4.8), "greater individual capacity and willingness to perform" (4.8) and "greater consideration for individual working-hour requirements" (4.6) are important factors which led to the implementation of flexible working-hour models. Similarly, company-oriented factors such as "better use or expansion of operating hours" (4.7) as well as "adapting working hours to meet order fluctuations" (4.7) were considered comparatively important (cf. Fig. 3, p. 10). In contrast, the 
factors of "positive experience of other companies" (3.3) and "avoiding dismissals" (3.1) received relatively low assessments from respondents.

These results are striking since those people who are interested find a considerable number of articles in trade literature and the daily press on companies who have had positive experience with flexible working-hour models. In addition, various institutions regularly offer seminars and meetings which provide guidance on working-hour flexibility opportunities. Alongside the trade unions, an increasing number of employers can see the positive side of these ideas since working-hour flexibility is frequently seen as an option to soften the blow of the social consequences of restructuring, mergers and takeovers. As a result of the low assessment of the factor "positive experience of other companies" and "avoiding dismissals", it can, however, be assumed that arguments of this type appeared insufficiently convincing or unsuitable for the company to the heads of human resources interviewed. 


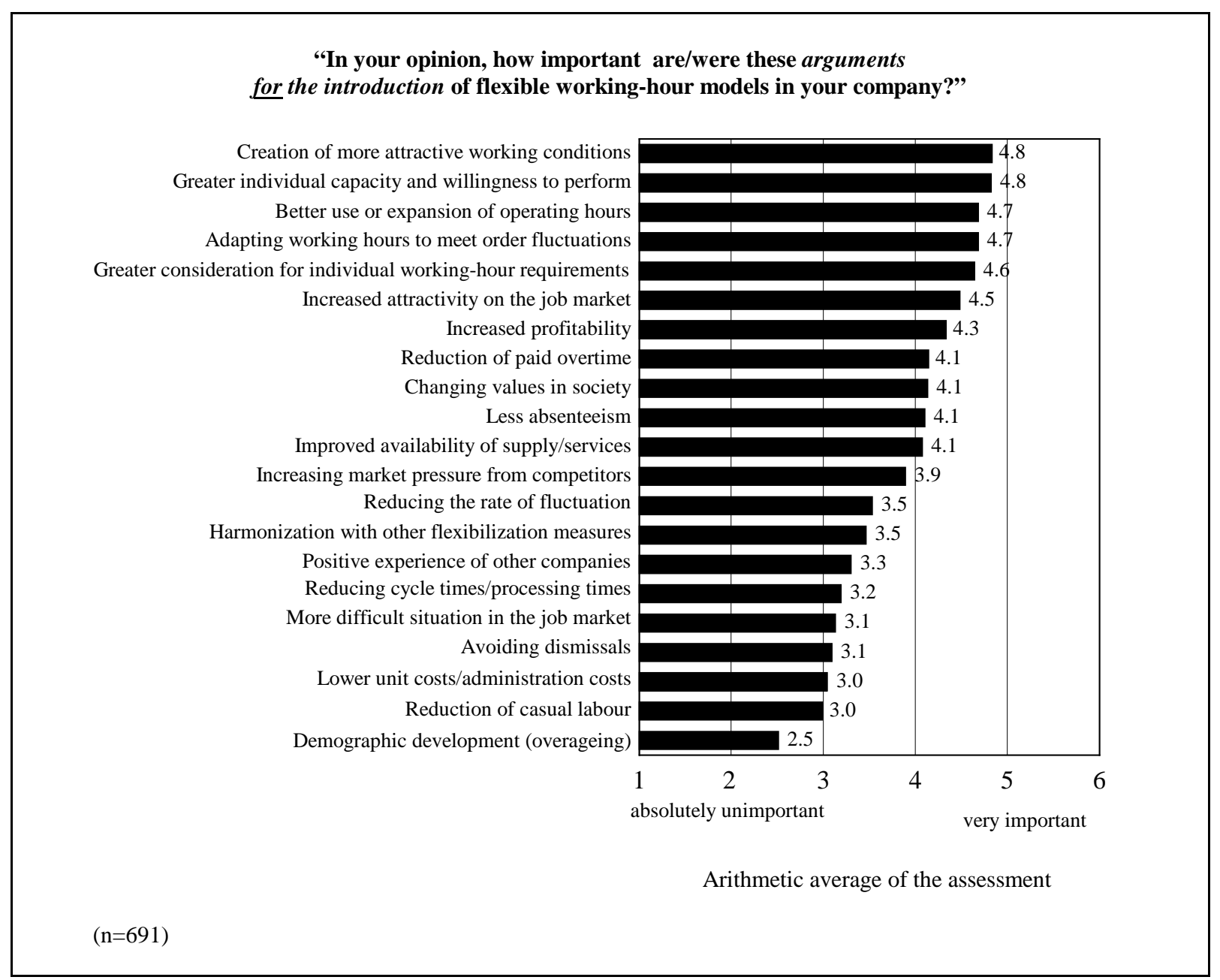

Fig. 3: $\quad$ Perceived influences on the introduction of flexible working-hour models

The factors "reduction of casual labour" (3.0) and "demographic development (overageing)" (2.5) have a "fairly unimportant" to "unimportant" influence on the introduction of flexible working-hour models.

The noticeably low assessment of the importance of demographic development might be attributable to respondents not having sufficiently recognized or considered social development: ${ }^{4}$ according to a wide variety of forecasts, a decrease in the younger potential labour force and an increase in the number of older employees is anticipated for the coming decades, independent of the immigration rate. The demographic ageing of the population is currently accompanied by a demographic rejuvenation of company workforces. It would appear plausible that the older generation, seen against both the entire population and the working popula- 
tion, will gain increasingly in importance and will thus make up an important part of tomorrow's potential workforce. This fact offers new challenges for personnel policies which will have to adjust to long-term difficulties when hiring younger persons and, at the same time, will have to align its personnel hiring and keeping activities with older employees. Flexible working-hour models - for example, extending working life upwards or gradual retirement combined with gradual employment for younger staff (relay models: passing on the "baton" from older to younger employees) - could provide possibilities for dealing with this development.

\section{b) Negative influential factors}

The following relates to factors which speak against the introduction of flexible working-hour models. Statements made by companies with flexible working-hour models are contrasted with those without flexible working-hour models (cf. Fig. 4, p. 12).

According to the respondents from companies with flexible working hours, the arguments "greater outlay on coordination" (4.2), "increased demands made on personnel management" (4.1), "endangering assured response times" (3.9) as well as "adverse effect on the flow of information and cooperation" (3.6) were the main reasons for rejecting the introduction of models of this type.

In the case of the arguments "greater outlay on coordination" and "endangering assured response times" (3.9) as well as "adverse effect on the flow of information and cooperation", these are typical start-up problems which can be solved by various measures after a period of adaptation (e.g. by increased harmonization among those affected, by institutionalized meetings, etc.). The relatively high weighting of the factor "increased demands made on personnel management" is probably attributable to ability or inclination barriers on the part of managers: the introduction of some types of flexible working hours make certain demands on executive 
skills which had previously been unnecessary for them to fulfil their duties. The following examples reinforce this assumption: fewer opportunities for supervision as a result of different working hours of staff require a new management approach based on trust. In addition, the individual responsibility on the part of employees, which is additionally made necessary by flexible working-hour regulations, should be promoted in order to ensure that the new freedom of action is sensibly used. This requires the relevant management abilities (e.g. coaching). Likewise, more demanding working organization measures are inevitable in order to reduce the danger of overlapping tasks, for example.

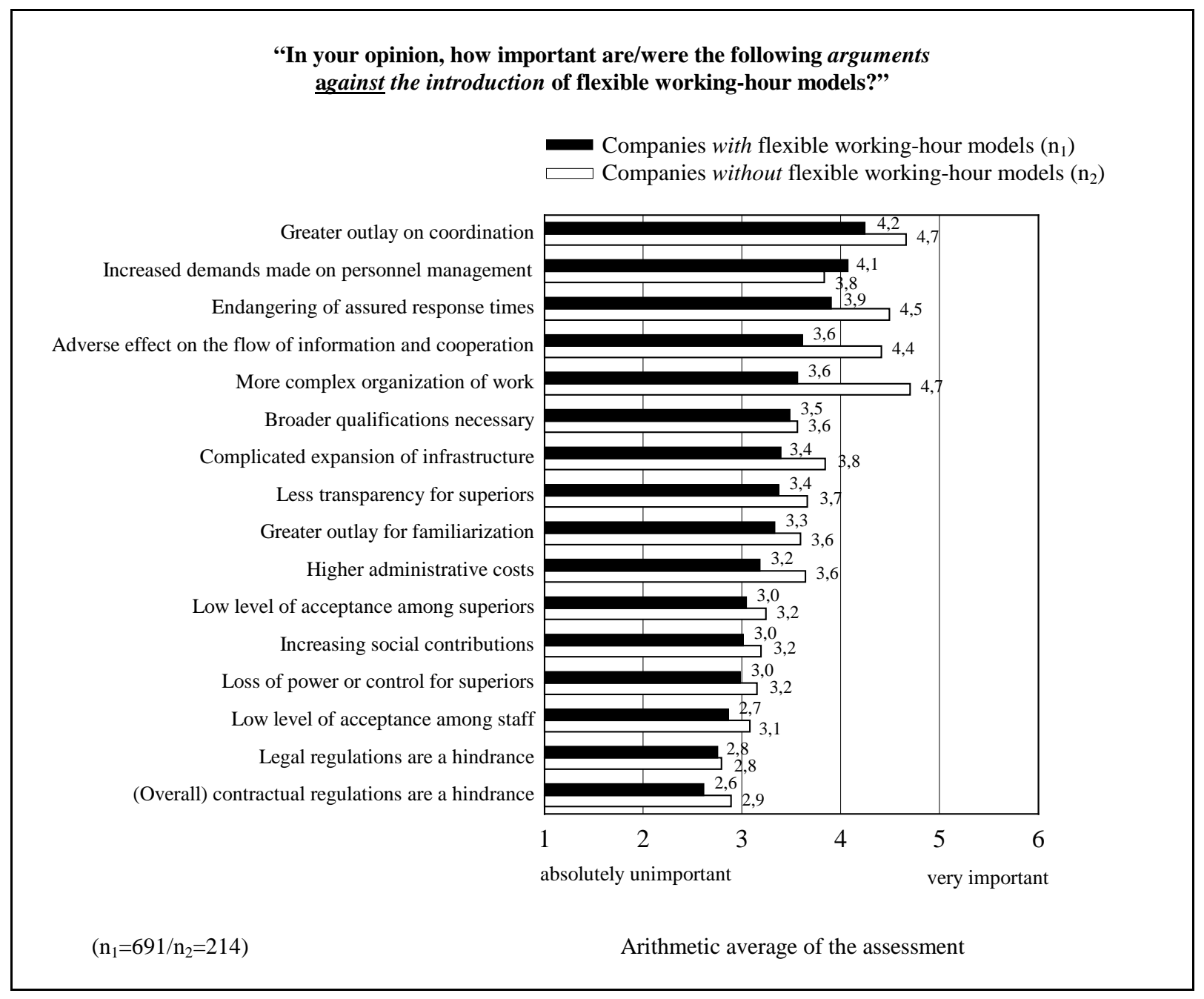

Fig. 4:

Perceived influences against the introduction offlexible working-hour models

In companies with an exclusively traditional regulation of working hours, organizationoriented problems, in particular, discourage the introduction of flexible working-hour models: 
the main arguments given were primarily "more complex organization of work" (4.7), "greater outlay on coordination" (4.7), the "endangering of assured response times" (4.5) and "adverse effect on the flow of information and cooperation" (4.4) (cf. Fig. 4, p. 12).

Personnel managers in both survey groups consider the prevention of introducing flexible working-hour models by legal $(2.8 / 2.8)$ or contractual $(2.6 / 2.9)$ regulations to be comparatively unimportant. Apparently, existing legal regulations provide sufficient room to manoeuvre in order to implement progressive solutions in working-hour structures.

\section{CONCLUSION}

Over three quarters of the companies included in the survey already use flexible working-hour models or are planning their introduction in the near future. In spite of a high proportion of companies with flexible working-hour models, however, it should not be forgotten that, as a rule, only a fairly small and select number of employees can benefit from these models.

Staff-related factors such as the creation of more attractive working conditions represent equally important aspects for the introduction of flexible working-hour models as do purely company-related factors (e.g. better use or expansion of operating hours). In contrast, sociocultural developments were not considered to be very important. As arguments against the use of flexible working-hour models, organizational aspects such as the more complex organization of work or irregular response times were stated. Legal or contractual regulations only play an unimportant role as hindrance factors.

The personnel managers surveyed see a large amount of potential for flexibilization that has not yet been fully exploited. Additional flexibility in terms of factors relating to company departments (increased differentiation) and variation in the length of working hours (chronome- 
try) as well as a more distinct adaptation of working-hour regulations to meet employees' requirements (increased autonomy for staff) are considered to be the most important demands made on working-hour structure in the future.

\section{Remarks}

1 Cf. Blum, Adrian: Arbeitszeitgestaltung in schweizerischen Unternehmungen, Working Report No. 18 of the Institute for Organization and Personnel of the University of Berne, Berne 1996.

2 As a result of the large number of publications on the features of individual working-hour models, a detailed bibliography on this is not included. The only reference is to a comprehensive basic text. Cf. Baillod, Jürg et al. (1993): Handbuch Arbeitszeit. Perspektiven, Probleme, Praxisbeispiele, 2nd edition, Zurich 1993.

3 The percentages in the text show the number of companies in each case in which the working-hour model is used in at least one case (multiple mentions were possible; $n=691$, i.e. only companies with flexible workinghour models either in place or planned).

4 Cf. Brachinger, Hans Wolfgang/Carnazzi, Sara/Thom, Norbert/Blum, Adrian: Eine Herausforderung für die Personalpolitik. Die demographische Entwicklung erfordert neue Arbeitszeitmodelle. In: iomanagement, 66th year, 1997, issue no. 9, pp. 18 - 23. 